\title{
A spectroscopy and microscopy study of Parylene-C OFETs for explosive sensing
}

Sandeep G. Surya ${ }^{1,2,5^{*}}$ Member, IEEE, Sunil Kumar Samji ${ }^{2}$, Dhamini P ${ }^{3}$, BS Pavan Ganne ${ }^{3}$, Prashant Sonar ${ }^{* *}$, V. Ramgopal Rao, ${ }^{1,2}$ Fellow, IEEE 
${ }^{1}$ Centre for Research in Nanotechnology and Science, Indian Institute of Technology Bombay, Mumbai 400 076, India

${ }^{2}$ Centre of Excellence in Nanoelectronics, Indian Institute of Technology Bombay, Mumbai 400 076, India

${ }^{3}$ Department of Electronics, Vignan's University, Vadlamudi, Guntur 522213, India (INUP IITB)

${ }^{4}$ School of Chemistry, Physics and Mechanical Engineering, Queensland University of Technology (QUT), 2, George Street GPO Box 2434, Brisbane, Australia

5 MST - Microsystems Technology Research Unit, Centre for Materials and Microsystems (CMM), Fondazione Bruno Kessler, Trento 38123, Italy.

*Corresponding author: Email sgs@ee.iitb.ac.in, sonar.prashant@qut.edu.au

\section{ABSTRACT:}

In this paper, we have explored Parylene-C (PC) as a sensing material for its unique signatures and selectivity for explosive sensing. We have used a bilayer deposition process to fabricate bottom-gate-topcontact (BGTC) OFET structures. Opening of dangling bonds on subjecting PC to plasma oxidation (POPC) renders these molecules to be employed as a receptor material in sensing vapors of both explosives and nonexplosives such as Trinitrotoulene (TNT), 1,3,5 trinitro1,3,5-triazacyclohexane(RDX), PETN, Dinitrobenzene $(\mathrm{DNB})$, Nitrobenzene (NB), Benzoquinone (BQ) and Benzophenone (BP). The change in (a) the vibration modes of the molecule by infrared spectroscopy (FTIR) (b) surface potential of POPC by Kelvin Probe Force Microscopy (KPFM) and (c) electrical characterization by IV measurements of PC based OFET on exposing to vapors have been systematically studied. Different signatures for all the analytes have been observed while exact and perfect selectivity for TNT, RDX were found from I-V studies and for PETN by KPFM studies. Thus, the OFET device based chemical sensors demonstrated here with improved sensitivity and excellent selectivity, stand as promising candidates for explosives detection.
Keywords: OFET, explosive detection, Parylene-C, sensor, plasma oxidation.

\section{INTRODUCTION:}

The fact that terror threats have posed great danger to human lives creates a great demand for sensitive and selective sensing of explosives. A whole gamut of explosive materials, the number of ways these explosives can be deployed, lack of inexpensive techniques with high selectivity and sensitivity for explosives, lack of easily detectable signatures has made detecting trace explosive a complex process. Hence an effort in addressing these problems is critical in fighting explosive based terror attacks. Among various explosives TNT, RDX, PETN and TATP (recently) are the most frequently used explosives. Chemical sensors used for the detection of these explosives have received greater importance due to issues related to security, mining and construction. There exist different technologies used for fabricating such sensing devices which are briefly discussed below, including the advantages and disadvantages associated. Concurrently, organic material based sensing devices were explored and have been discussed in detail with respect to the detection of explosives. Additionally, organic materials are soft and printable upon a variety of substrates for building flexible prototypes.

There are several reports on various types of sensors used for selective detection of explosives with high sensitivities [1], for e.g., a low-cost Sinanocomposite coated paper based sensor for nitro aromatic compounds [2], an array of sensors, where each element of the array is a field effect-like transistor to detect triacetone triperoxide (TATP) [3], a colorimetric sensor array to detect the vapor of TATP with limits of detection below 2 (parts per billion) [4] etc. Using sensors such as ion mobility spectrometers [5] or electron capture detectors, high vapor pressure explosives can be detected easily. Surface swiping can be employed to detect medium vapor pressure explosives [6]. However, low vapor pressure explosives are difficult to detect and 
highly sensitive and selective platforms need to be employed to detect such compounds. By heating them, the vapor pressure of such compounds can be increased [7]. Temperatures should be raised with in the permitted limits and for generation of necessary amount of vapor (concentration). There is therefore a great need for explosive detectors that offer the advantages of lower cost, fewer processing steps, better selectivity, portability and capability for detecting low vapor pressure compounds.

OFETs have been well researched for their electrical properties as active devices [8-10] and in OLED displays $[11,12]$. Though they could not be released into the market, analog circuits were realized using these OFETs in the literature [13-15]. OFET applications have also forayed into gas sensors research [16-19] with the help of different polymers and their composites. In addition, OFET sensors are also used for radiation sensing. Different organic materials and their composites were used in the past as radiation sensors. Despite many applications, OFET devices are prone to degradation as their semiconductors are organic. In our previous study, a low temperature $\mathrm{Si}_{3} \mathrm{~N}_{4}$ layer has been shown as an effective passivation layer for pentacene. However, employing such an insulation layer for chemical sensors is not desirable as they disrupt analyte interactions. In order to make the devices robust (nondegradable) and to make them perform sensing functions, we need to explore novel materials and platforms. Parylene-C (PC) is a polymer generally used to encapsulate materials, which are prone to degradation, thus enhancing their lifetime. In 2008 Song et al, used parylene with subsequent plasma treatment to improve biocompatibility of implantable medical device [20]. In 2010, T.H Ham et al., did Inductively Coupled Plasma (ICP) etching of $\mathrm{PC}$ with $\mathrm{O}_{2}$ and $\mathrm{CF}_{4}$ mixture. As a consequence, it was concluded that oxygen radical density caused the etching and not the carbon containing species [21]. PC was also considered as a low-K dielectric material with dielectric constant around $\sim 3.1$ at $1 \mathrm{KHz}$ [22]. Due to its low dielectric constant (low$\mathrm{K})$, PC dielectric was used in applications like OFETs [23] and graphene FETs [24]. Later, A Kahouli et al., incorporated fluorine atoms in the PC structure to lower dielectric constant to increase the thermal stability and hydrophobicity [25]. While no application has been developed, Trantidou et al., have discussed about hydrophilicity in the PC films and explained how hydrophilicity varied with varying power intensity and time of exposure [26]. In 2013, Trantidou et al., came up with $\mathrm{pH}$ monitoring application using PC [27]. Orthogonal sensor array system (with arrays of different OFETs) was employed for early warning of explosives. Our earlier work for detecting same analytes was reported with different channel materials [28] and with different blends [29].

Table. 1 Limit of detection, response time of various organic semiconductors used in different geometries are listed in the table

\begin{tabular}{|c|c|c|c|c|}
\hline Author & $\begin{array}{l}\text { Organic } \\
\text { semi- } \\
\text { conductor }\end{array}$ & Geometry & LOD (Analyte) & Response time \\
\hline E.Bentes [30] & $\mathrm{DH} 4 \mathrm{~T}$ & $\mathrm{BGBC}$ & -- (TNT) & $\sim 5$ minutes \\
\hline R S Dudhe[31 ] & $\mathrm{P} 3 \mathrm{HT}$ & BGBC & 500 ppt (TNT), 700 ppt (RDX) & -- \\
\hline Thomas [32] & $\begin{array}{l}\text { PQT 12/ } \\
\text { NTCDI }\end{array}$ & BGTC & $--(\mathrm{DNT})$ & $\sim 4$ minutes \\
\hline Hunag[33 ] & 6РТTР6 & BGTC & 5 ppm (DMMP) & $\sim 4$ minutes \\
\hline Akhtar [34] & CPNs & BGTC & $\begin{array}{l}30.99 \mathrm{pM} / 7.07 \mathrm{ppt}(\mathrm{PA} \text { in } \\
\text { aqueous medium) }\end{array}$ & $\sim 6$ seconds \\
\hline A. Kalita [35] & NDMI & -- & 2.92 PPT (PA) & 8 seconds \\
\hline G. Tang[36] & Dendrimer & BGTC & $200 \mathrm{ppm}(\mathrm{pNT})$ & 15 seconds \\
\hline our work & $\mathrm{P} 3 \mathrm{HT} / \mathrm{PC}$ & BGTC & $\begin{array}{l}16 \mathrm{ppb}, 56 \mathrm{ppb} \text { and } 39 \mathrm{ppb} \text { for } \\
\text { TNT, RDX and PETN (KPFM) } \\
\text { and for OFET at } 70 \mathrm{C} \text { heating }\end{array}$ & $\begin{array}{l}<2 \text { minutes }(\mathrm{KPFM}), \\
<3 \text { minutes }(\mathrm{OFET})\end{array}$ \\
\hline
\end{tabular}


Herein, we have reported a bi-layer OFET in which the PC layer acts as an encapsulation till it is used, protecting the sensitive organic semiconductor from degradation. During the test phase, the top parylene layer was subjected to plasma oxidation for 2 minutes. This process opened up dangling bonds, as discussed in the following section, making it sensitive for interaction with analytes. Parylene plays a double role - before plasma exposure it acts as an encapsulation layer but upon plasma oxidation it acts as an analyte absorbing layer. Change in the vibration properties, surface potential and electrical properties of POPC on exposure to different analytes such as explosives are studied by FTIR, KPFM and I-V characterization respectively. Here, degradation resistance and reusability are important properties that make PC a competent material for OFET based sensors. Table 1 shows a clear comparison between the present work and other works reported earlier, using different OFETs, Limit Of Detection (LOD) and response times. In this work, BGTC device geometry with highly doped Si acting as a gate at the bottom was used. Detection of explosives with the OFETs is still in its nascent stage as can be seen from the table. E Bentes [30] and Thomas et al. [32] have not reported on their limit of detection and RS Dudhe [31] provides no information on response time. Akhtar [34] and A. Kalita [35] used phenol based explosive called picric acid (PA). For the selectivity study, the nitro aromatic compounds used were in 500 ppb range. Similarly, G. Tang [36] used dendrimer for the detection of $p$-nitrotoluene ( $\mathrm{pNT}$ ), where the LOD was in ppm range.

\section{EXPERIMENTAL SECTION:}

\section{OFET Sensor Fabrication and Characterization:}

A bottom gate top contact OFET was fabricated with highly doped n-type $\mathrm{Si}$ ([100] orientation) as substrate. The procedure of fabrication for OFET was followed as discussed in our earlier study [37]. The back of the OFET (Si) was covered with insulation tape and on the top a passivating PC layer was deposited on the OFET to stop degradation of active channel semiconductor materials poly(3hexylthiophene) P3HT. Additionally, in order to pattern the PC layer, the parallel gold electrodes (source and drain) were partially covered using thermal insulation tape under the microscope. White crystals of Parylene$\mathrm{C}$ dimer (Figure 1a) (precursor) were used to deposit a $500 \mathrm{~nm}$ layer of Parylene-C (PC) polymer. After Chemical Vapour Deposition (CVD) of PC, the thermal insulation tape was peeled off and plasma ashing was done as required. This helped probe the contact pads during electrical measurements. The insulation tape at the back of OFET the gate from PC deposition and was later removed (the gate probing would have been obstructed during current-voltage (I-V) measurements). Final structure of the bi-layer OFET is shown in Figure 1c. Once PC was deposited by CVD on top of P3HT, these devices were stored in the vacuum desiccators to

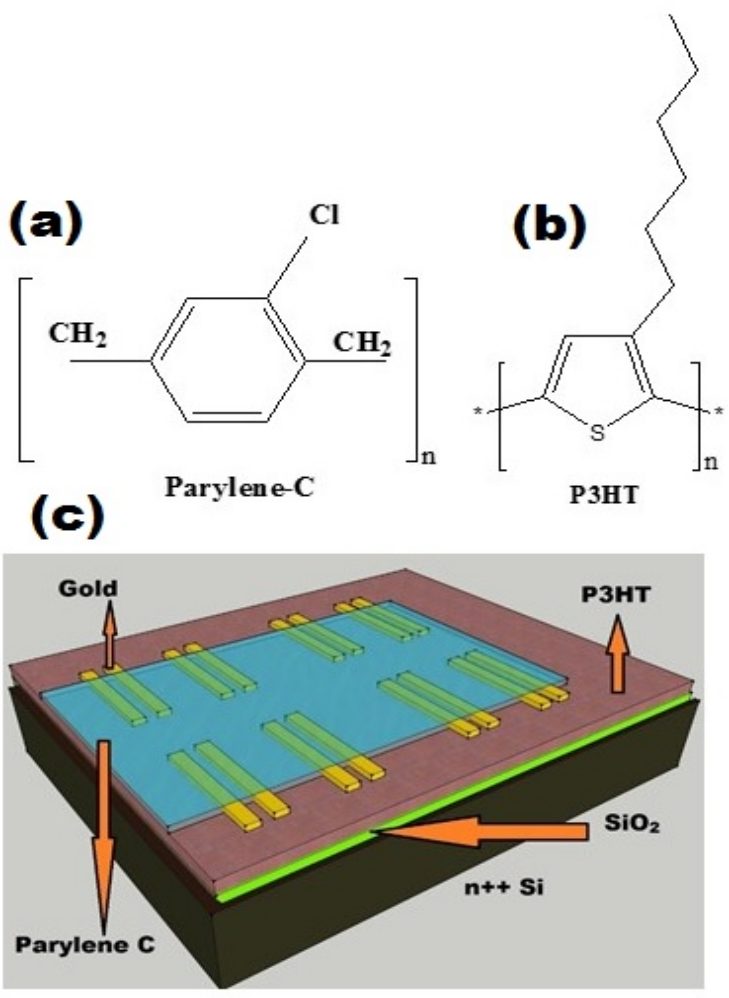

be used when required.

Figure 1. Chemical structure of (a) Parylene-C (b) P3HT (c) OFET device structure with Parylene-C used as encapsulating layer.

The thin films of PC were subjected to plasma ashing using plasma asher from Harrick Plasma, Inc. While the effect induced by oxygen plasma can last for up to 30 days in inert conditions, there is a considerable change noticed in 7 days when exposed to atmosphere. Thus, the sensors can either be plasma oxidized before the test, or can be stored in an inert environment up to 30 days after plasma oxidation. Regaining the hydrophobicity over a period (greater than 30 days) is a self-limiting phenomenon of PC surface. The increased number of pin holes and uneven morphology while gaining the hydrophobicity hinder the employability of $\mathrm{PC}$ in further sensing activities. Hence, after the sensing application, unused POPC devices are plasma ashed completely to re-fabricate the devices. The vibrational modes of the Plasma Oxidized Parylene-C (POPC) 
surface exposed to different analytes were analyzed with Fourier Transform Infra-Red Spectroscopy (FTIR, Spectra 100, Perkin Elmer). The I-V characteristics were measured using Agilent B1500 semiconductor device analyzer; the data was collected for POPC OFETs separately before and after exposure to various analytes. Surface potential images of POPC were recorded using KPFM, Asylum MFP-3D SPM to find the change in Contact Potential Difference (CPD) on exposure to different analytes. The desired concentrations of the different analytes were generated using Vapor generator (OWLSTONE, OVG 4) by adjusting the temperature.

\section{RESULTS AND DISCUSSION:}

\section{FTIR Studies:}

It is known that vibrational modes of a molecule or lattice are unique and a characteristic feature of the molecule. For chemical identification, vibrational spectroscopy technique such as FTIR is a critical tool as the fingerprints of the molecule/interaction can be found in the vibrational spectra. The vibrational mode of the molecule is very sensitive to the functional group attached and can change depending on the group functionalized. In the present study, when POPC is being used for sensing analytes (of both explosive and non-explosives), molecules of the analytes are also being sensed by the POPC. Any vibrational modes of POPC will be affected by the analyte and a characteristic change in vibrational mode is anticipated. Song et al., [20] and J.S Cho et al. [38] have reported that PC, when subjected to plasma oxidation, the inert surface becomes

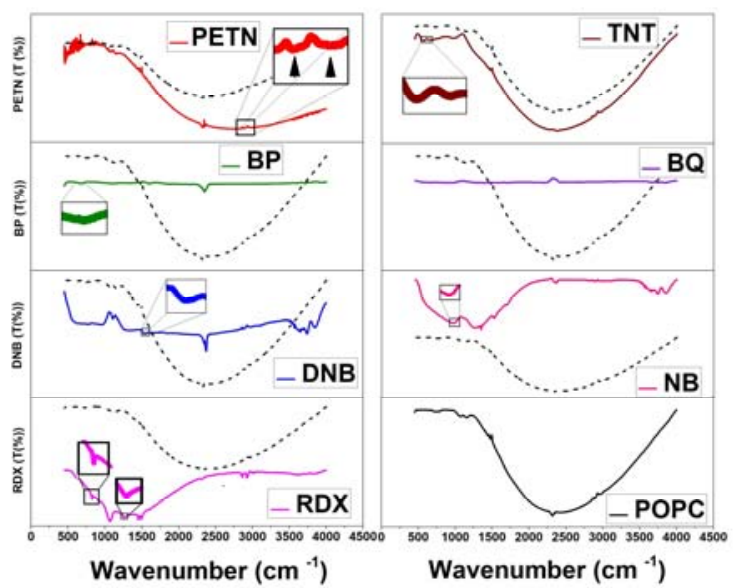

Figure 2. FTIR spectra of different analytes exposed to POPC surfaces (a) PETN (b) TNT (c) BP (d) BQ (e) DNB (f) NB (g) RDX and (h) pristine POPC surface. (Dotted line is POPC) highly sensitive with the opening of $\mathrm{C}=\mathrm{O}, \mathrm{C}-\mathrm{O}$, $\mathrm{O}-\mathrm{C}=\mathrm{O}, \mathrm{C}-\mathrm{O}-\mathrm{O}$ and $\mathrm{CO}_{3}$ etc. polar bonds. The interaction of these bonds with different analytes provides a specific finger print characteristic of the analyte as shown in Figure 2 along with the tabulated corresponding modes and analytes.

Figure 3 shows the chemical structures of different analytes used in this experiment which include, both, explosives and non-explosives. The characteristic mode of transmission for PETN exposed POPC appear at 2800 to $3300 \mathrm{~cm}^{-1}$ due to three bands, N-H and O-H stretching vibration. In case of TNT, characteristic mode of transmission band can be observed between $600-675 \mathrm{~cm}^{-1}$ and $542-595 \mathrm{~cm}^{-1}$ arising due to stretching vibration of $\mathrm{N}-\mathrm{C}=\mathrm{O}$.

1. POPC exposed to RDX finger print regions appear at $1235-1275$ and $800-835$ due to asymmetric $\mathrm{NO}_{2}$ stretching owing to the formation of inorganic nitrate salts.

2. NB $\mathrm{C}-\mathrm{C}$ stretching vibration can be observed between $960-1000 \mathrm{~cm}^{-1}, 490-595 \mathrm{~cm}^{-1}, 890-930 \mathrm{~cm}^{-1}$.

3. $\mathrm{C}-\mathrm{H}$ stretching vibration at $2850-2870 \mathrm{~cm}^{-1}, 2950-$ $2960 \mathrm{~cm}^{-1}$.

4. DNB $\mathrm{N}-\mathrm{H}$ bending vibration can be observed at 1500-1590.

5. $\mathrm{BP}$ and $\mathrm{BQ} \mathrm{NH} 2$ stretching mode between 1220$1305 \mathrm{~cm}^{-1}$. An out of plane $\mathrm{NH}$ deformation vibration between $620-770 \mathrm{~cm}^{-1}$ can be observed.

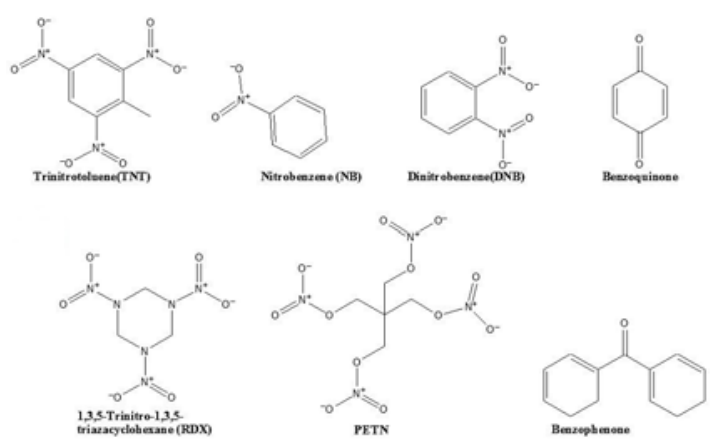

Figure 3. Chemical structure of all the analytes with individual names

FTIR spectra of POPC exposed to different analyte molecules, clearly exhibits different patterns (Table. 2). There is a similarity in the patterns between POPC and TNT FTIR data. This is due to similar chemical functional groups such as sidely substituted methyl group and aromatic phenylene present in both chemical structures (TNT and POPC). The amount of analyte vapour present in the POPC thin film is diffusion controlled which results in the FTIR analysis as expected. In order to support the observations, additional characterizations were performed. Secondary 
Ion Mass Spectroscopy (SIMS) studies have also been carried out on PC and POPC to understand the role of plasma oxidation in creating dangling bonds. This is discussed in supporting information S3.

Table. 2 Shows different analytes exposed to the POPC layer and the corresponding bond stretches.

\begin{tabular}{|c|l|l|}
\hline Analyte & $\begin{array}{l}\text { Significant peak } \\
\text { wave number } \\
\left(\mathbf{c m}^{-\mathbf{1}}\right)\end{array}$ & \multicolumn{1}{|c|}{ Bond } \\
\hline PETN & $2800-3300$ & $\begin{array}{l}\text { N-H and O-H } \\
\text { stretching } \\
\text { vibration }\end{array}$ \\
\hline TNT & $\begin{array}{l}600-675 \& 542- \\
595\end{array}$ & $\begin{array}{l}\text { stretching } \\
\text { vibration of } \\
\text { N-C=O }\end{array}$ \\
\hline RDX & $\begin{array}{l}1235-1275 \& \\
800-835\end{array}$ & $\begin{array}{l}\text { asymmetric } \mathrm{NO}_{2} \\
\text { stretching }\end{array}$ \\
\hline NB & $\begin{array}{l}960-1000 \& 490- \\
595\end{array}$ & $\begin{array}{l}\text {-C stretching } \\
\text { vibration }\end{array}$ \\
\hline & $2850-2870 \&$ & $\begin{array}{l}\text { C-H stretching } \\
\text { vibration }\end{array}$ \\
\hline DNB & $1500-2960-1590$ & $\begin{array}{l}\text { N-H bending } \\
\text { vibration }\end{array}$ \\
\hline BQ \& BP & $1220-1305$ & NH2 stretching \\
\hline & $620-770$ & $\begin{array}{l}\text { out of plane NH } \\
\text { deformation } \\
\text { vibration }\end{array}$ \\
\hline & & \multicolumn{2}{|c|}{} \\
\hline
\end{tabular}

OFET Sensing Analysis:

OFETs with P3HT as an active channel semiconductor material is used for chemical sensing (Figure 1b) [37]. PC is known to be hydrophobic and inert; however, its nature can be changed to hydrophilic and reactive during oxidation. Incidences of oxidation of PC has been reported through different techniques; K.G Pruden et al., used UV light [39], D.J Monl et al., used tempering [40], J.H Lee[41] and D.A. Shutov used plasma treatment [42]. In general, for a given polymer the sensitivity varies from one analyte to another. In order to improve the sensitivity, PC has been subjected to $\mathrm{O}_{2}$ plasma treatment before testing. The RF power during the ashing is maintained at 18Watts for 2 minutes (these values were arrived at after multiple trials and has been discussed in previous literature [26, 27]). Trantidou et al., already proved that longer $\mathrm{O}_{2}$ plasma treatment has led to an increased hydrophilicity, thereby leading to better sensitivity towards $\mathrm{H}^{+}$. It can be also inferred that thicker membranes of PC are more hydrophobic in nature thereby causing a decreased sensitivity.
Transfer and output characteristics on the POPC OFET were studied using Agilent B1500 semiconductor device analyzer. For the p-type device, sweep voltage applied at drain terminal was varied from 0 to $-35 \mathrm{~V}$ with a step size of $-0.5 \mathrm{~V}$ while the gate voltages were swept from 0 to $-25 \mathrm{~V}$ with a step size of $5 \mathrm{~V} . \mathrm{I}_{\mathrm{DS}}-\mathrm{V}_{\mathrm{DS}}$ characteristics (supporting Figure S2) were obtained by grounding the source terminal. The transfer characteristics were obtained from the $\mathrm{I}_{\mathrm{DS}}-\mathrm{V}_{\mathrm{GS}}$ plots. The gate voltage was varied from 0 to $-35 \mathrm{~V}$ with a step of $-0.5 \mathrm{~V}$ while varying the drain voltages from 0 to $25 \mathrm{~V}$ with a $-5 \mathrm{~V}$ step size. For the present bi-layered device, the saturated drain current $\left(\mathrm{I}_{\text {Dsat }}\right)$, On-Current $\left(\mathrm{I}_{\mathrm{on}}\right)$ and OFF currents $\left(\mathrm{I}_{\mathrm{off}}\right)$ were considered as parameters of interest, which were obtained from the above characteristics. As the vapor pressure of the analytes at room temperature is low, analytes were heated to $70{ }^{\circ} \mathrm{C}$ for testing and the $\mathrm{I}-\mathrm{V}$ characteristics of OFETs were obtained before (BF) and after (AF) exposure to various analytes. The complete characterization was carried out in real time (at room temperature approximately $26^{\circ} \mathrm{C}$ ). Exposure of analytes was done for 2 minutes as this allows the devices under test to receive adequate concentration of analytes to pass through. All possible parameters were extracted from I$\mathrm{V}$ studies, while the ON currents $\left(\mathrm{I}_{\mathrm{on}}\right)$ and OFF currents $\left(\mathrm{I}_{\mathrm{off}}\right)$ were derived directly from the $\mathrm{I}_{\mathrm{DS}}-\mathrm{V}_{\mathrm{GS}}$ curve. The presence of analytes was clearly identified from the distinct changes, which were observed in the key parameters as shown in Figure 4.

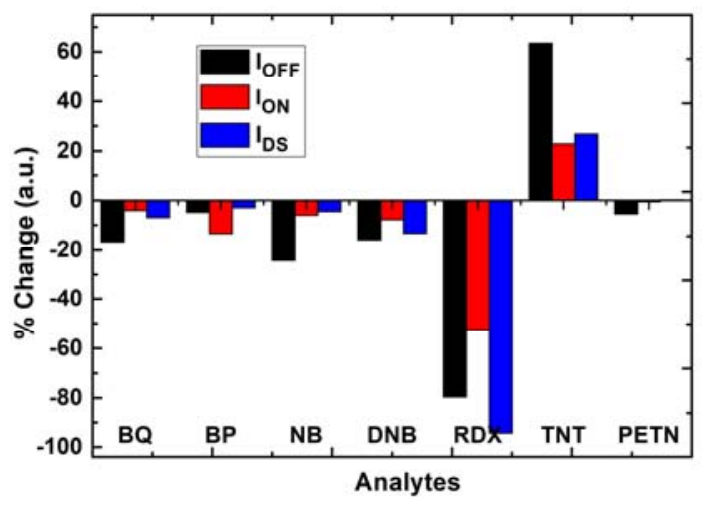

Figure 4. Bar-graph of OFET with (\% change) parameters corresponding to different analytes heated to $70^{\circ} \mathrm{C}$

Figure (S1) shows the bar graphs of transistor parameters $\left(\mathrm{I}_{\mathrm{ON}}, \mathrm{I}_{\mathrm{OFF}}\right.$ and $\left.\mathrm{I}_{\mathrm{DS}}\right)$ with $\mathrm{PC}$ layer on top. It was observed that the PC based OFET does not respond to explosives like TNT and RDX but responds to PETN and BP. Whereas, as shown in Figure 4, POPC based OFETs responded to explosives like TNT and RDX in terms of their parameters. The change in $\mathrm{I}_{\mathrm{ON}}$ and $\mathrm{I}_{\mathrm{DS}}$ currents depend on the nature of interaction of the 
analytes with free radicals created on the surface of POPC. $\mathrm{I}_{\mathrm{OFF}}$ is highly susceptible nature to minute variations in the environment and voltage bias. In case of $\mathrm{BQ}, \mathrm{BP}, \mathrm{NB}$ and $\mathrm{DNB}$ the changes in $\mathrm{I}_{\text {on }}$ and $\mathrm{I}_{\mathrm{ds}}$ have less effect owing to the quenching of free radicals. PETN when it interacts with the radicals $(\mathrm{C}=\mathrm{O}, \mathrm{C}-\mathrm{O}$, $\mathrm{O}-\mathrm{C}=\mathrm{O}, \mathrm{C}-\mathrm{O}-\mathrm{O}$ and $\mathrm{CO}_{3}$ etc polar bonds) forms $\mathrm{OH}$ group (alcohols) and $\mathrm{NO}_{2}$ radical is liberated as gas. The surface is then neutralized and quenching occurs immediately. However, RDX generates more radicals as compared to other analytes. They form unstable hyperactive intermediaries that are short-lived and tend to unify into the bulk of the device to stabilize. These intermediaries then consume the holes of the $\mathrm{P} 3 \mathrm{HT}$ and stabilize by reducing/diminishing the conduction in P3HT layer. Hence, the currents in both, transfer and output characteristics, after exposing to RDX diminish, leaving behind their significant features. In case of TNT, the intermediaries generated due to interaction with radicals are highly stable in nature and are inclined to increase the hole concentration unlike RDX. In the structure of the TNT, 2 ortho and 1 para positions are attacked by radicals and form stable charged intermediaries. These intermediaries go to the bulk of P3HT and contribute to the conduction there by increasing the channel currents.

P3HT is a p-type material and can be easily doped with external impurities as its oxidation onset or HOMO level is higher. It is similar to p-type and n-type doping in silicon wafers. Usually the conductivity in the organic semiconductors is explained using band diagrams, here we used shifting of HOMO and LUMO positions for the same. Figure 5 (a) shows the case of unexposed P3HT where HOMO and LUMO levels are maintained at $5.2 \mathrm{eV}$ and $3.2 \mathrm{eV}$; PETN exposed P3HT (minimal change, where HOMO level is at $5.2 \mathrm{eV}$. (b) In the case of TNT, there is an increase in the accumulation of holes in the channel due to shift of $\mathrm{HOMO}$ level in an upward direction $(\mathrm{HOMO}<5.2 \mathrm{eV})$.
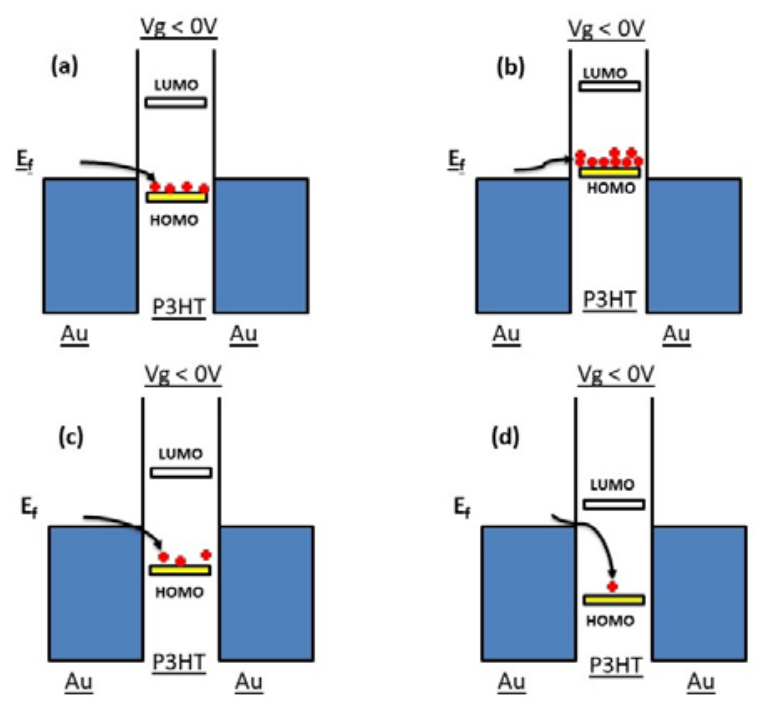

Figure 5. Conductivity changes and corresponding HOMO and LUMO levels after exposure to analytes (a) for P3HT (b) for TNT (c) for BP, BQ, NB, DNB and (d) for RDX.

(c) For other analytes (BQ,BP,NB,DNB) the drain current decreases slightly as the HOMO level drops down relatively (HOMO slightly $>5.2 \mathrm{eV}$ ). (d) For $\mathrm{RDX}$ the drain current diminishes as there is a drastic change in HOMO level (HOMO $>>5.2 \mathrm{eV})$.

\section{KPFM Analysis:}

Since sensing of analytes by POPC is a surface phenomenon, KPFM studies were carried out to understand the change in CPD on exposure to analytes. Surface potential distribution images of POPC stack, before and after exposure to different analytes (RDX, PETN, DNB, TNT, NB, BQ, BP), were recorded using two pass Kelvin probe force microscopy (KPFM) technique using Asylum MFP-3D SPM with Ti/Ir coated $\mathrm{Si}$ tips. The work function of the tip was calibrated using standard HOPG sample; the work function is known $(4.60 \mathrm{eV})$ by using the equation:

$$
\emptyset_{\text {tip }}-\emptyset_{\text {sample }}=e .(C P D) \rightarrow 1
$$

where CPD is contact potential difference and $\emptyset_{\text {tip }}, \emptyset_{\text {sample }}$ are work functions of the tip and sample respectively.

A signature change in surface potential for each molecule was anticipated and possible selectivity of POPC for a particular explosive explored. There have been some reports on using Kelvin Probe Microscopy for gas sensing applications. Moos et al, have reported change in work function of $\mathrm{G}_{2} \mathrm{O}_{3} / \mathrm{Pt}$ and $\mathrm{BaCO}_{3}$ upon exposure to $\mathrm{CO}$ (carbon monoxide) [43]. Smaali et al, have reported Kelvin Probe Microscopy studies for surface characterization of in-operando Si nano ribbon field effect transistors (SiNr-FETs) for detection of 
organic phosphorous [44]. However, no studies on surface potential studies of plasma oxidized Parylene C as a sensor for detection of explosives using KPFM, have been reported. The present study is an effort to understand the change in contact potential difference of POPC on exposure to different analytes (explosives and non-explosives). Figure. 6a shows equivalent circuit diagram for KPFM studies on $\mathrm{Si} / \mathrm{SiO} 2 / \mathrm{P} 3 \mathrm{HT} / \mathrm{POPC}$ samples before and after exposure to different analytes.

It can be observed that bare Parylene has positive surface potential and plasma oxidized $\mathrm{PC}$ has a negative surface potential (Figure. 6b). This change in surface potential can be due to opening up of dangling bonds after plasma ashing. It can be observed that POPC has clear selectivity for PETN, while the surface potential in different analytes remains negative; but in the case of PETN, a positive surface potential is observed. To further validate this, the surface potential image for explosives was recorded by evaporating the materials at different

(a)
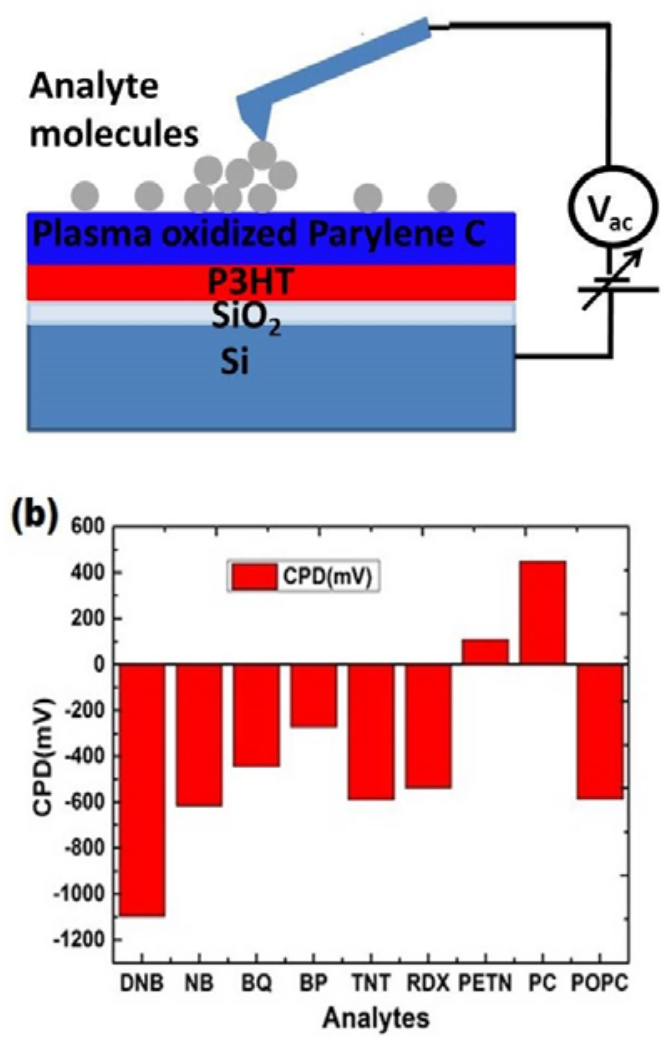

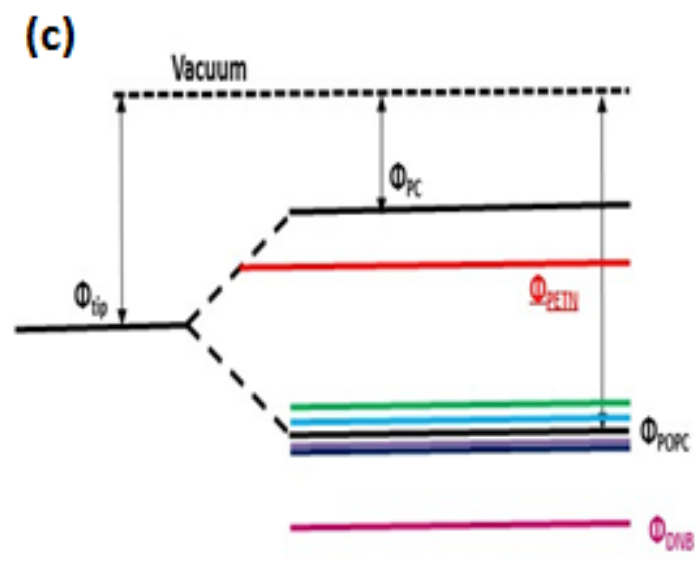

Figure 6. (a) Equivalent circuit diagram for KPFM studies of plasma oxidized $\mathrm{Si} / \mathrm{SiO} 2 / \mathrm{P} 3 \mathrm{HT} /$ Parylene-C and (b) Bar chart generated with average contact potential difference obtained using KPFM. (c) Energy level schematic derived from CPD values from KPFM measurements on exposing various analytes to POPC along with bare Parylene are shown.

temperatures and then measuring the amount of analytes released from the outlet of the Owlstone vapor generator set up. As the concentration of the gases increases with increasing temperature, POPC sees a higher concentration of explosive analytes at the outlet of the OWLSTONE vapor generator. The surface potential images were then recorded with analyte exposed POPC. It was observed that with increasing concentration of analytes, there was an increase in the CPD values recorded on exposed POPC. However, the increment was not that pronounced in case of TNT as the increase in concentration for this analytes was not high/uniform with temperature. Rewriting the equation 1 for $\mathrm{PC}$, it can be observed that $\emptyset_{t i p}-\emptyset_{P C}=(450 \mathrm{meV})$ is positive. However, after plasma ashing it has been ascertained that CPD between tip and POPC is changing to a negative value. This is a signature that plasma ashing is rendering the surface electron rich, consequentially reducing the surface potential of POPC (as compared to PC). The corresponding energy level diagram showing the change in surface potential of POPC is represented in Figure. 5c. Also, the energy levels for different analytes exposed POPC (by plugging in the values of CPD in equation 1 for different analytes).

It is very important for us to understand the sensing nature of POPC in normal ambience and explore its performance as a real-time sensor. Hence tests were performed in normal ambience and under controlled environment, using vapor generator, with $\mathrm{N}_{2}$ as a carrier gas. For all the characterizations except vapour generator studies (1 minute), the analyte vapours were exposed for 2 minutes at room temperature and ambience. 


\section{CPD measurements using OWLSTONE vapor generator:}

The fabricated stack structures followed by plasma oxidation were also subjected to different analyte vapors. An owlstone OVG-4 vapor generator was operated to generate TNT, RDX and PETN vapors with $\mathrm{N}_{2}$ as a carrier gas. The setup consists of individual permeation tubes for each analyte. Upon heating, the vapors diffuse through the walls of tube into the carrier gas. Keeping the flow rate of $\mathrm{N}_{2}$ gas constant at 50 SCCM, the corresponding permeation rates of TNT, RDX and PETN were maintained at $123 \mathrm{ng} / \mathrm{min}, 152$ $\mathrm{ng} / \mathrm{min}$ and $152 \mathrm{ng} / \mathrm{min}$, and exposed for a minute. The corresponding molecular weights of TNT, RDX and PETN analytes used in permeation tubes were 227 $\mathrm{g} / \mathrm{mol}, 222 \mathrm{~g} / \mathrm{mol}$ and $316 \mathrm{~g} / \mathrm{mol}$ respectively. Calibration temperatures used to set the concentrations for the above analytes were $100^{\circ} \mathrm{C}, 80^{\circ} \mathrm{C}$ and $80^{\circ} \mathrm{C}$ respectively. Though the sources are solid, the concentration of the analyte at the sensor can be manipulated by parameters like temperature, split-flow and sample flow. It is a known fact that the concentration of TNT is 4 orders of magnitude higher compared to RDX and PETN (in the range of RT to 100 ${ }^{\circ} \mathrm{C}$ ). In order to bring concentration of analytes in same order, the split flow feature in vapour generator (exclusively TNT) was employed. The sample flow has remained unchanged, as has the permeation rate at the same calibrated temperature. The $\mathrm{ng} / \mathrm{min}$ was diluted into a larger flow (mL), but the excess flow was discarded. Thus, the three analytes have a slight difference in factor (2-3) and not in orders as shown in Figure.7a.
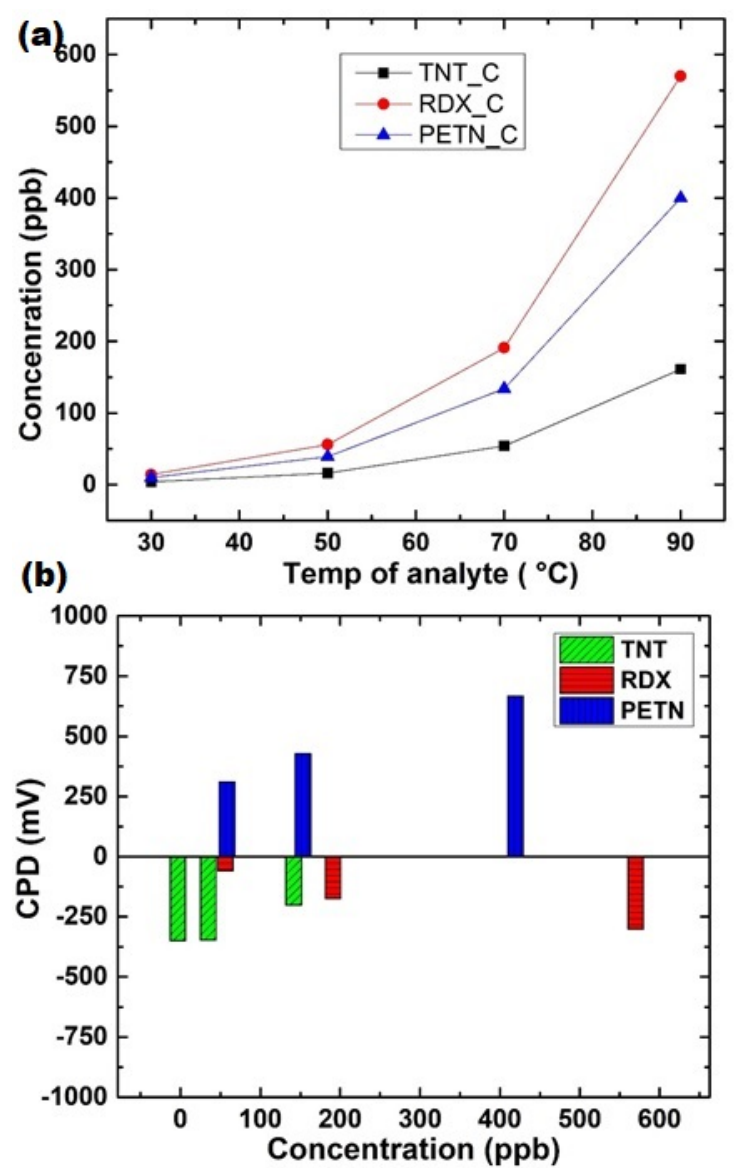

Figure 7. (a) Concentration variation of explosives with temperature (OWLSTONE) (b) Bar chart generated with average contact potential difference obtained for explosive at different concentrations.

The lowest concentrations generated for TNT, RDX and PETN are $16 \mathrm{ppb}, 56 \mathrm{ppb}$ and $134 \mathrm{ppb}$ respectively. As shown in Figure $7 \mathrm{~b}$, the CPD values were plotted with respect to the concentration of analytes. A control run performed proved that the carrier gas $\mathrm{N}_{2}$ had no effect on the CPD values at varying temperatures. CPD of PETN was showing a unique signature and was increasing in the same fashion with concentration, which is a function of temperature. The figure also depicts that the response CPD values of RDX and TNT exposed devices are in opposite direction, thus showing a clear indication of signature. Opening up of the dangling bonds renders higher electron density at the surface in case of POPC as compared to PC (no localized electrons). This is the reason for observed negative surface potential (high workfunction). Most explosives are known to be electron hungry and among the three, PETN compound has highest electronegativity (EG). i.e., EG-PETN > EG-RDX > EG-TNT. This implies in the presence of PETN, the localized electrons on dangling bonds tend to neutralize and the tip observes higher potential (positive CPD). 
Finally, in this work, we discuss a sufficiently novel transduction methodology similar to olfactory system. PC based OFET is analogous to an Olfactory Receptor Neuron (ORN) of the biological nose. The sensor, interacts with the analytes and passes the transduced signal for data analysis. In this case, multiparametric analysis was done with the analytes heated at $70^{\circ} \mathrm{C}$ as shown in Figure 3b. Data mining techniques were used to classify the analytes as explosives and non-explosives. Similarly, we show that the POPC thin film based KPFM study has its own merits in classifying certain analytes from its CPD values as can be seen from figures $6 \mathrm{~b} \& 7 \mathrm{~b}$. We also notice that analyte properties vary significantly with different physical parameters and accordingly the pre-calibration of the setup needs to be done.

\section{CONCLUSIONS:}

Herein, we have reported use of plasma oxidized Parylene- $\mathrm{C}$ as a sensing layer for explosives. Explosive and non-explosive analytes were used for testing. FTIR studies revealed unique signatures for different analytes. $I_{o n}, I_{\text {off }}$ and $I_{D S}$ currents of OFETs showed selectivity for TNT and RDX, while surface potential determination from KPFM studies revealed selectivity for PETN (generating a positive CPD). The limit of detection of the explosives with the use of Owlstone vapor generator was around $16 \mathrm{ppb}, 56 \mathrm{ppb}$, $39 \mathrm{ppb}$ for TNT, RDX and PETN respectively and the corresponding sensitivities are $3.67 \mathrm{mV} / \mathrm{V} / \mathrm{ppb},-6.02$ $\mathrm{mV} / \mathrm{V} / \mathrm{ppb}$ and $8.9 \mathrm{mV} / \mathrm{V} / \mathrm{ppb}$. Studying the possibility of immobilizing different receptor molecules on top of POPC, there can be a future prospect of this work in exploring bio-sensing applications.

\section{References:}

[1] Bielecki, Z., Janucki, J., Kawalec, A., Mikołajczyk, J., Pałka, N., Pasternak, M., Pustelny, T., Stacewicz, T. and Wojtas, J., 2012. Sensors and systems for the detection of explosive devices-an overview. Metrology and Measurement Systems, 19(1), pp.3-28.

[2] Gonzalez, Christina M., Muhammad Iqbal, Mita Dasog, Davin G. Piercey, Ross Lockwood, Thomas M. Klapötke, and Jonathan GC Veinot. "Detection of high-energy compounds using photoluminescent silicon nanocrystal paper based sensors." Nanoscale 6, no. 5 (2014): 2608-2612

[3] Eyal Capua, Roberto Cao, Chaim N. Sukenik, Ron Naaman, Detection of triacetone triperoxide (TATP) with an array of sensors based on non-specific interactions, Sensors and Actuators B: Chemical, Volume 140, Issue 1, 18 June 2009, Pages 122-127
[4] Hengwei Lin and Kenneth S. Suslick, A Colorimetric Sensor Array for Detection of Triacetone Triperoxide Vapor, Journal of the American Chemical Society 2010132 (44), 15519-15521

[5] Kanu, A.B., Dwivedi, P., Tam, M., Herbert, L.M., Hill, H. (2008). Ion mobility-mass spectrometry. Mass Spectrom., 43, 1-22. Wiley Inter Science (www.interscience.wiley.com) DOI:10.1002/jms.1383.

[6] Reno, J., Fisher, R.C., Robinson, L., Brennan, N., Travis, J. (1999). Guide for the selection of commercial explosives detection systems for low enforcement application. U.S. National Institute of Justice. Washington.

[7] Östmark, H., Wallin, S. and Ang, H. G. (2012), Vapor Pressure of Explosives: A Critical Review. Propellants, Explosives, Pyrotechnics, 37: $12-23$.

[8] Tsumura, H. Koezuka, and K. Ando, Macromolecular electronic device: Field- effect transistor with a polythiophene thin film, Appl. Phys. Lett., 49 (1986) 1210-1212.

[9] A. Assadi, C. Svensson, M. Willander, and O. Inganas, Field effect mobility of poly (3-hexylthiophene), Appl. Phys. Lett., 53 (1988) 195198.

[10] J. Paloheimo, P. Kuivalainen, H. Stubb, E. Vuorimaa, and P. Y. Lahti, Molecular field effect transistor using conducting polymer Langmuir-Blodgett films, Appl. Phys. Lett., 56 (1990) 1157-1159.

[11] Kyungbum Ryu, "Characterization of Organic Field Effect Transistors for OLED displays", M.S Thesis, Dept of EECS, MIT, Cambridge, Massachusetts, USA, 2005.

[12] Furno, M., Kleemann, H., Schwartz, G. and Blochwitz Nimoth, J., Late News Paper: Vertical Organic Transistors (V OFETs) for Truly Flexible AMOLED Displays, SID Symposium Digest of Technical Papers, 46-1 (2015) 597-600.

[13] C. J. Drury, C. M. J. Mutsaers, C. M. Hart, M. Matters, and D. M. Lee, Ultrafast optical switching by photoinduced electrochromism in cast films of polymeric 4,48-bipyridinium salts with di-iodides, Appl. Phys. Lett., 73 (1998) 108 characteristics of parylene-C films in an inductively coupled O2/CF4 gas plasma, Thin Solid Films, Volume 518, Issue 22, 1 September 2010, Pages 6378-6381

[14] S. R. Forrest, The path to ubiquitous and low-cost organic electronic appliances on plastic, NATURE, 428 (2004) 911.

[15] Z. Bao, Materials and Fabrication Needs for Low-Cost Organic Transistor Circuits Adv. Mater., 12 (2000) 227.

[16] J. J. Miasik, A. Hooper, and B. C. Tofield, Conducting polymer gas sensor, J. Chem. Soc., Faraday Trans. 1, 82 (1986) 1117-1126.

[17] A. Assadi, G. Gustafsson, M. Willander, C. Svensson, and O. Inganas, Determination of field-effect mobility of poly(3hexylthiophene) upon exposure to $\mathrm{NH}_{3}$ gas, Synth. Met., 37 (1990) 123-130.

[18] H. Fukuda, M. Ise, T. Kogure, and N. Takano, Gas sensors based on poly-3-hexylthiophene thin-film transistors, Thin Solid Films, 464465 (2004) 441-444.

[19] L. Torsi, A. Dobalapur, L. Sabbatini, and P. G. Zambonin, Multi-parameter gas sensors based on organic thin-film-transistors, Sens. Actuators B, 67 (2000) 312-316.

[20] Song, J. S., Lee, S., Jung, S. H., Cha, G. C. and Mun, M. S. (2009), Improved biocompatibility of parylene-C films prepared by chemical vapor deposition and the subsequent plasma treatment. J. Appl. Polym. Sci., 112: 3677-3685. 
[21] Yong-Hyun Ham, Dmitriy Alexandrovich Shutov, Kyu-Ha Baek, Lee-Mi Do, Kwangsoo Kim, Chi-Woo Lee, Kwang-Ho Kwon, Surface

[22] Kahouli A, Sylvestre, Ortega L, Jomni F, Yangui B, Maillard M, Berge B, Robert J C and Legrand J 2009 Appl. Phys. Lett. 94152901

[23] J. Jakabovič, J. Kováč, M. Weis, D. Haško, R. Srnánek, P. Valent, R. Resel, Preparation and properties of thin parylene layers as the gate dielectrics for organic field effect transistors, Microelectronics Journal, Volume 40, Issue 3, March 2009, Pages 595-597

[24] Sabri S S, Levesque P L, Aguirre C M, Guillemette J, Martel R and Szkopek T 2009 Appl. Phys. Lett. 95242104

[25] A Kahouli, A Sylvestre, J-F Laithier, S Pairis, J-L Garden, E André, F Jomni and B Yangui, Effect of $\mathrm{O} 2, \mathrm{Ar} / \mathrm{H} 2$ and $\mathrm{CF} 4$ plasma treatments on the structural and dielectric properties of parylene-C thin films, Journal of Physics D: Applied Physics,45-21, 2012

[26] Tatiana Trantidou, Themistoklis Prodromakis, Chris Toumazou, Oxygen plasma induced hydrophilicity of Parylene-C thin films, Applied Surface Science, 261, 43-51, 2012

[27] Tatiana Trantidou, David J. Payne, Vasileios Tsiligkiridis, YuChun Chang, Christofer Toumazou, Themistoklis Prodromakis, The dual role of Parylene $\mathrm{C}$ in chemical sensing: Acting as an encapsulant and as a sensing membrane for $\mathrm{pH}$ monitoring applications, Sensors and Actuators B: Chemical, 186, 1-8, 2013.

[28] Sandeep G. Surya, Sanjog S. Nagarkar, Prashant Sonar, Sujit K. Ghosh,V. Ramgopal Rao, "An Explosive detection sensor based on an Organic Field Effect Transistor using diketopyrrolopyrrole and metal organic framework polymer composite", Sensors \& Actuators B: Chemical (Elsevier), Volume 223, February 2016, Pages 114-122

[29] Sandeep G. Surya, Ravishankar S. Dudhe, Deepak Saluru, Bharath Kumar Koora, Dinesh K. Sharma, V. Ramgopal Rao, "Comparison among different algorithms in classifying explosives using OFETs", Sensors \& Actuators B: Chemical (Elsevier), Volume 176, January 2013, Pages 46-51

[30] Bentes, E., Henrique L. Gomes, Peter Stallinga, and L. Moura. "Detection of explosive vapors using organic thin-film transistors." In Sensors, 2004. Proceedings of IEEE, pp. 766-769. IEEE,

[31] Ravishankar S. Dudhe, Jasmine Sinha, Anil Kumar and V. Ramgopal Rao,"Polymer composite-based OFET sensor with improved sensitivity towards nitro based explosive vapors", Sensors \& Actuators: B. Chemical, Volume 148, Issue 1, 30 June 2010, Pages $158-1652010$

[32] T. J. Dawidczyk, J. Huang, J. Sun, T. Shastry, A. Mason and H. E. Katz, "Organic field-effect transistor sensors with dual responses to dinitrotoluene," 2009 International Semiconductor Device Research Symposium, College Park, MD, 2009, pp. 1-2.
[33] Huang, J., Miragliotta, J., Becknell, A., and Katz, H. E., Hydroxy-Terminated Organic Semiconductor-Based Field-Effect Transistors for Phosphonate Vapor Detection, J. Am. Chem. Soc. 129, 9366-9376 (2007)

[34] A.H. Malik, S.Hussain, A.Kalita, and P.K.Iyer, Conjugated Polymer Nanoparticles for the Amplified Detection of Nitro-explosive Picric Acid on Multiple Platforms, ACS Applied Materials \& Interfaces 20157 (48), 26968-26976

[35] A.Kalita, S.Hussain, A.H. Malik, U.Barman, N.Goswami, and P.K.Iyer, Anion-Exchange Induced Strong $\pi-\pi$ Interactions in Single Crystalline Naphthalene Diimide for Nitroexplosive Sensing: An Electronic Prototype for Visual on-Site Detection,ACS Applied Materials \& Interfaces 20168 (38), 25326-25336

[36] G. Tang, Simon S.Y. Chen, M. Aljada, Paul L. Burn, Paul Meredith, Paul E. Shaw, Detection of explosive analytes using a dendrimer-based field-effect transistor, In Organic Electronics, 2013 14(5), 1255-1261

[37] Sandeep G. Surya, Ashwath Narayana B S, Sushma Mishra, Karthik A R B, Sastry A B, Prasad B L V, Dinesh Rangappa, V Ramgopal Rao, H2S detection using low-cost $\mathrm{SnO} 2$ Nano-particle Bilayer OFETs, Sensors \& Actuators B: Chemical, 235,378-385, 2016.

[38] J.S. Cho, Young-Whoan Beag, Sung Han, Ki-Hwan Kim, J. Cho, Seok-Keun Koh, Hydrophilic surface formation on materials and its applications, Surface and Coatings Technology,128-129, 66-70, 2000.

[39] K.G. Pruden, K. Sinclair, S. Beaudoin, Characterization of parylene-N and parylene-C photooxidation, J. Polym. Sci. A, Polym. Chem. 41 (2003) 1486-1496

[40] D.J. Monk, H.S. Toh, J. Wertz, Oxidative degradation of parylene $\mathrm{C}$ (poly(monochloro-para-xylylene)) thin films on bulk micromachined piezoresistive silicon pressure sensors, Sens. Mater. 9 (1997) 307-319

[41] J.H. Lee, D.S. Yoon, T.S. Kim, I. Han, J.H. Noh, Effect of atmosphericplasma treatments for enhancing adhesion of $\mathrm{Au}$ on parylene-c-coated protein chips, J. Korean Phys. Soc. 44 (2004) 11681172 .

[42] D.A. Shutov, S.Y. Kang, K.H. Beak, K.S. Suh, K.H. Kwon, Influence of $\mathrm{Ar}$ and $\mathrm{NH} 3$ Plasma Treatment on Surface of Poly(monochloro-para-xylylene) Dielectric Films Processed in Oxygen Plasma, pn. J. Appl. Phys. 47 (2008) 6970-6973.

[43] Ralf Moos, Kathy Sahner, Maximilian Fleischer, Ulrich Guth, Nicolae Barsan and Udo Weimar, Solid State Gas Sensor Research in Germany - a Status Report Sensors 9(6) (2009) 4323-4365

[44] Smaali, K., Guerin, D., Passi, V., Ordronneau, L., Carella, A., Mélin, T., Dubois, E., Vuillaume, D., Simonato, J.P. and Lenfant, S., 2016. Physical Study by Surface characterizations of Sarin Sensor on the Basis of Chemically Functionalized Silicon Nanoribbon Field Effect Transistor. The Journal of Physical Chemistry C, 120(20) (2016) 11180-11191. 